\title{
ASSESSMENT AND TEST IN TEACHING AND LEARNING
}

\author{
Kedar Prasad Sah \\ Department of English Education, TU, TRM Campus, Birgunj \\ Email: kp_sah@yahoo.com
}

\begin{abstract}
Needless to mention that assessment is an indispensable part of teaching and learning. This article is an attempt to explain how teaching, learning and assessing are intimately interrelated. However, it primarily focuses on the crucial role of assessment in enhancing teaching and learning in general and English language teaching in particular. While doing so, assessment has been compared to testing which is more often used in the Nepalese academia.
\end{abstract}

\section{Keywords}

Teaching, learning, testing, assessing, wash back effects.

\section{Introduction}

It is a well known fact that teaching and learning are complementary to each other. Teaching (the process of giving knowledge or instructing) and learning (the process of receiving knowledge or skill) appear simultaneously, and there we also need some measures to ensure learning in consonance with teaching. There are various terminologies that are often used interchangeably, i.e. test, examination, evaluation, assessment, measurement. They can be differentiated from each other in several ways. However, that is not the concern of this paper. In this paper, I have made an attempt to show how assessment and test differ from each other. I have also tried to emphasize that testing is required to be replaced by assessment since the latter is wide ranging and has several advantages over the former. I also discuss the implications of employing assessment in place of testing in English language teaching.

\section{Assessment and test}

Of the two terms, test is no doubt, much more common than assessment. In our context, 'assessment' is relatively a less used term than 'test' for many teachers, students and guardians. The term 'test' is simple and understandable to everyone involved in teaching and learning. Even the illiterate parents are heard of speaking that their 
children are preparing for a test or a test is going on at the nearby school. Though assessment is a less frequently used word, truly it is broader and more comprehensive than test. Mousavi (2009) has stated assessment as "apprising or estimating the level or magnitude of some attribute of a person", which signifies how fundamentally assessment is attached to someone's some quality or skill (cited in Brown and Abeywickrama, 2010, p. 3). Yet, it is something that is sometimes mistaken for test in educational practice. Test is particular - it focuses on some particular task. On the other hand, assessment is general, as well as particular - it goes hand in hand with teaching including test. Whenever teaching starts, almost all the teachers keep observing and judging students' interest and performance knowingly and unknowingly. Even students judge their improvement as compared to their peers. They also make some comments on the ways teachers do teaching. In course of teaching there may arise several questions followed by answers, and then interactions like 'Why this? Why not that?' quizzes or questionnaires to be answered in limited time, and so on. All those activities structure the feedback on the class, helping to bring some modification in further teaching. All those formal or informal measures that are aimed at tailoring teaching for better learning are known as assessments. There are different kinds of assessments, such as formal and informal assessments, formative and summative assessments, and all the tests.

Test, on the other hand, is a specific assessment or a particular form of assessment, for assessment includes test as its subset (Hughes, 2003; Brown and Abeywickrama, 2010). Test is a process that is administered to measure student's ability to performance in a particular field in a certain time limit with some specific goal. It generally acts as a gatepass in teaching for students to go ahead in learning. In the sections that follow, I analyze whether assessment can be of broader utilities in favour of learning.

\section{Teaching, learning and test}

Whenever there is learning, there precedes teaching and test appears at certain intervals. Mostly test appears after some teaching, but sometimes it seems to be arranged before some teaching. For example, proficiency test, placement test, diagnostic test and aptitude test are supposed to take place before students start a course. Thus, it is comprehensible that the students who take the test must have done some learning through some kind of teaching beforehand, so that they would like to find out whether they deserve a particular course or level, or so that what kind of course is to be designed to meet learners' needs. Nevertheless, what most of us are familiar with about test is achievement test that is arranged on the completion of certain course or part of course so as to measure how far the students have achieved or commanded the lesson or lessons they have been taught. Sorrowfully, such tests as argued by Hughes (2003) are mostly of poor quality leaving harmful effects on teaching and learning. The impact of test on teaching and learning, which may be positive or negative, or rather beneficial or harmful, is linguistically known as 'washback'. Why are tests often of poor quality? Why do they generally have harmful washback? It signifies that preparing a test is not so simple. Until tests are designed to meet the objectives of teaching a course or teaching is shaped and carried out as per the needs of tests, they will remain horrible. When it comes to the tests of a language course, it is much more challenging to prepare good tests, which are considered to be really good if they are based on the five principles known as the principles of language assessment. In other words, a good test or assessment is the one that has validity, reliability, practicality, authenticity and beneficial washback in a balanced way. And, an English language test designed to administer on the completion of certain session is meant for gauging learners' command over the four skills of language, namely listening, speaking, reading and writing. A question arises: Are test users doing 
overall justice especially in our context, as far as the test of English subject is concerned? After class ten, students seem to have been proficient listeners, speakers and readers; and what is left for them to master is only writing. That is why they have to take only written exam. Now it is important to have a few words about reading and writing. Brown (2004) has expressed "the uniqueness of writing as a skill with its own features and conventions", adding that it is an uphill task even for native learners to make their writing clearly logical and well-organized to serve an anticipated purpose (p. 218). On the other hand, Cohen (1994) has explained that reading is viewed as an interaction between the text and the reader. Now the query is: Are our students really cultivating their reading and writing skills accordingly? Aren't they just committing and vomiting? Their 'cut' and 'paste' practice not only mock their reading and writing abilities but also ruin their creativity and critical analysis. Incorporating seen reading passages in the examination further validates committing and vomiting trend in the Nepalese academia. Varieties of handbooks commonly known as guess papers of different courses are thought to lessen their 'burden' of having to face the challenges of 'reading' and 'writing' by serving ready-made answers. Students might yearn for the same because of the drawbacks in our own system. Khaniya (2005) hints that teaching is just focused on exam or test when there is "narrowing down curriculum into score producing area" and regular "use of previous exam papers leading to guesswork and memorization" (p. 61). Whatever is the so-called teaching for if it fails to cultivate 'genuineness' within the learners against 'fakeness'? Is it not about time we explored 'something else' within the domain of assessment, so that exam-centered teaching could be shifted to learning-centered one?

\section{Teaching, learning and assessment}

As mentioned earlier, teaching and learning go side by side. Today teaching should be learner-centered. No matter how excellent teaching might be, it is judged and awarded on the ground of learning, i.e. how effectively learning has occurred. That is the main reason that good teachers are always concerned about whether their teaching is making any sense, i.e. whether students are learning successfully or not.

The straight question is 'How do teachers find out how fruitful their teaching is?' Is there any measuring instrument? Yes, there is a method of judging what way the teaching is going, i.e. whether the students are satisfied and motivated to enhance learning. Teachers can constantlyapplyatechniquetoget thefeedback on their own teaching. And, it is assessment! Then, there might be a simple query 'What exactly is assessment? Does it mean asking questions, making students repeat a line or a word better and better, getting students to think and find out something appropriate, interaction with or among students to come to some logical conclusion, giving classwork and homework, giving a class test or something else? Now the answer is everything! Yes, it is assessment that may be very informal or formal, that may take place once a year or frequently in a single teaching period and that may take a few minutes or a few years. In course of assessing students' performance, teachers may also carry out 'measurement' by giving some marks or letter grades like $\mathrm{A}$, B, C, etc. They help students find out their comparative levels with encouragement. Besides measurement, there should be some written or verbal comment on the students' achievement like 'Very good/ good/ fair, which is known as evaluation. The following diagram shows the interrelationships between teaching, assessment, measurement, test and evaluation clearer.

When it comes to language testing, we have observed the narrow scopes of tests and felt the greater exploration beyond test within the periphery of assessment. If English language testing is aimed at the greater strength of communication, assessment must have nexus with real-world experiences. Other aspects of 


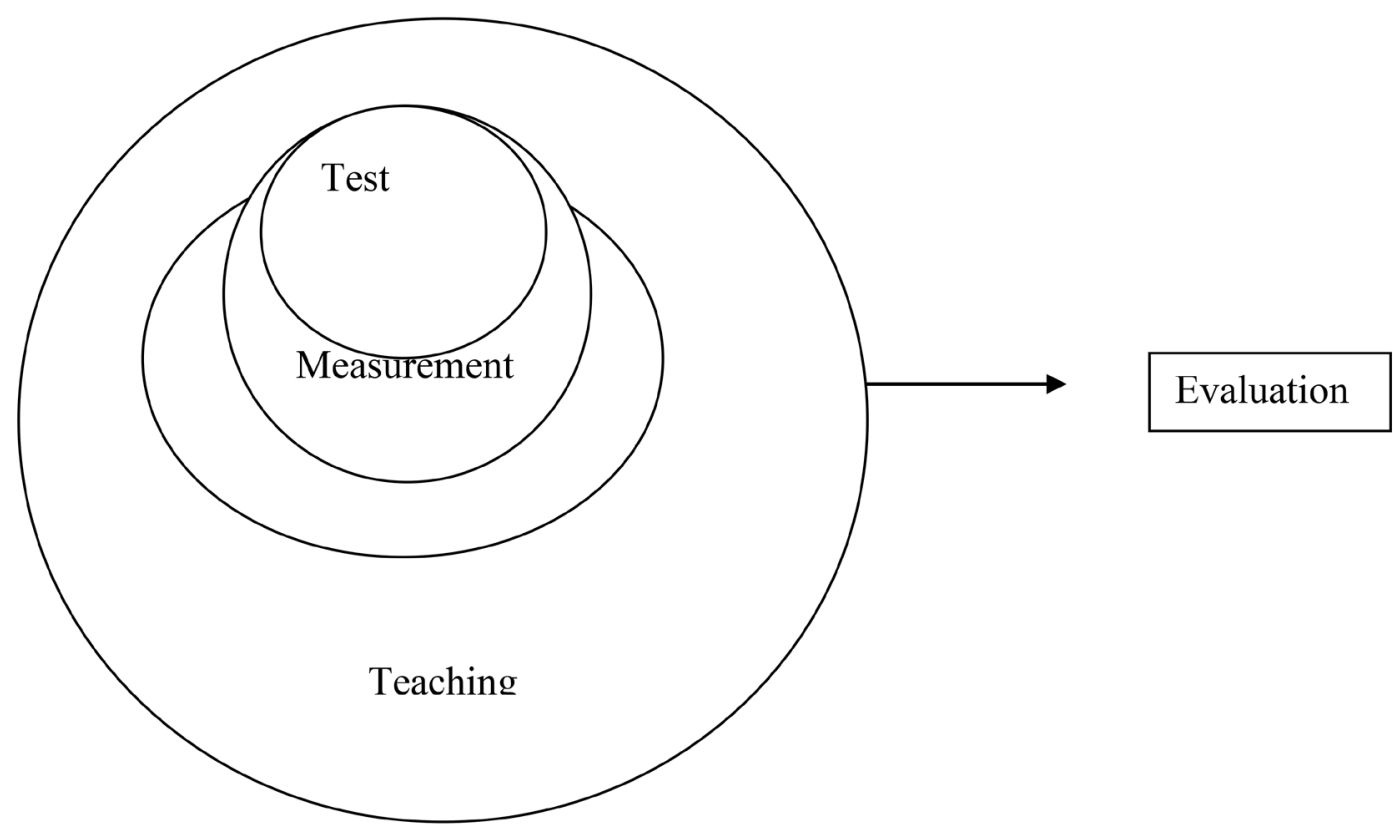

Figure: The Venn diagram shows the relationship among teaching, assessment, measurement, test and evaluation. (Brown and Abeywickrama, 2010)

assessment, i.e. authentic assessments, like oral interview, text retelling, portfolio, etc. could also be taken into consideration. Teachers can make a judicious selection in this regard to meet instructional and students' needs providing systematic information about student learning or about the goals of instruction (O’Malley and Pierce, 1996).

\section{Conclusion}

Learning, as well as teaching, is one of the most basic processes that human beings have had since their existence. And, assessment goes parallel to teaching and learning whether formally or informally. What tests and assessments have resulted in so far or would yield in the future can give a purposeful shape to teaching, as well as curriculum development. Now it is worth considering different aspects of assessment that might lead us to the new horizons of learning. Assessment could be felt to have potentiality to change the test takers' horrible conception on test which is administered in a certain period of time, or rather in some minutes or some hours. Such a time limitation is one of the causes that keep test takers tense and terrified until they take their test, because of which learners cannot be motivated to real learning. In order to have a remarkable change, instruction ought to be of its quality. If students are allowed to actively choose and do their work themselves, they will certainly find their jobs fun-giving, motivating and challenging. Precisely, it is project-based instruction in which students plan, implement and evaluate projects that have real-world applications beyond the classroom (Blank, 1997; Dickinson, et al. 1998; Harwell, 1997, cited in Railsback, 2002). That is why it is high time curriculum developers in our country have to pay attention to the brighter sides of assessment and its abundant practice for learners to have real enhanced learning.

\section{References}

Brown, H.D. (2004). Language assessment: Principles and classroom practices. White 
Plains, NY: Longman

Brown, H.D. and Abeywickrama, P. (2010). Language assessment: Principles and classroom practices ( $2^{\text {nd }}$ ed.). White Plains, NY: Pearson Education.

Cohen, A. (1994). Assessing language ability in the classroom ( $2^{\text {nd }}$ ed.). Boston, MA: Heinle \& Heinle

Hughes, A. (2003). Testing for language teachers (and ed.). Cambridge England: Cambridge University Press.
Khaniya, T.R. (2005). Examination for enhanced Learning. Kathmandu: Kishore Khaniya.

O’Malley, J.M and Pierce, L.V. (1996). Authentic assessment for English language learners: Practical approaches for teachers. Reading, MA: Addition-Wesley Publishing Company.

Railsback, J. (2002). Project-based instruction: Creating excitement for learning. Portland, Oregon: Northwest Regional Educational Laboratory. 